\title{
Solar System Exploration Augmented by In-Situ Resource Utilization: Human Mercury and Saturn Exploration
}

\author{
Bryan Palaszewski \\ NASA John H. Glenn Research Center \\ Lewis Field \\ MS 5-10 \\ Cleveland, $\mathrm{OH} 44135$ \\ (216) 977-7493 Voice \\ (216) 433-5802 FAX \\ bryan.a.palaszewski@nasa.gov \\ Fuels and Space Propellants Web Site: \\ http://www.grc.nasa.gov/WWW/Fuels-And-Space-Propellants/foctopsb.htm
}

Human and robotic missions to Mercury and Saturn are presented and analyzed. Unique elements of the local planetary environments are discussed and included in the analyses and assessments. Using historical studies of space exploration, in-situ resource utilization (ISRU), and industrialization all point to the vastness of natural resources in the solar system. Advanced propulsion benefitted from these resources in many way. While advanced propulsion systems were proposed in these historical studies, further investigation of nuclear options using high power nuclear thermal and nuclear pulse propulsion as well as advanced chemical propulsion can significantly enhance these scenarios. Updated analyses based on these historical visions will be presented. Nuclear thermal propulsion and ISRU enhanced chemical propulsion landers are assessed for Mercury missions. At Saturn, nuclear pulse propulsion with alternate propellant feed systems and Titan exploration with chemical propulsion options are discussed.

\section{Nomenclature}

$\begin{array}{ll}\text { 3He } & \text { Helium } 3 \\ \text { 4He } & \text { Helium (or Helium 4) } \\ \text { AMOSS } & \text { Atmospheric mining in the outer solar system } \\ \text { CC } & \text { Closed cycle } \\ \text { delta-V } & \text { Change in velocity (km/s) } \\ \text { GCR } & \text { Gas core rocket } \\ \text { GTOW } & \text { Gross Takeoff Weight } \\ \text { H2 } & \text { Hydrogen } \\ \text { He } & \text { Helium 4 } \\ \text { ISRU } & \text { In Situ Resource Utilization } \\ \text { Isp } & \text { Specific Impulse (s) } \\ \text { K } & \text { Kelvin } \\ \text { kWe } & \text { Kilowatts of electric power } \\ \text { LEO } & \text { Low Earth Orbit } \\ \text { MESSENGER } & \text { Mercury Space Surface ENvironment, GEochemistry, and Ranging } \\ \text { MT } & \text { Metric tons } \\ \text { MWe } & \text { Megawatt electric (power level) } \\ \text { NEP } & \text { Nuclear Electric Propulsion } \\ \text { NPP } & \text { Nuclear Pulse Propulsion }\end{array}$

* Leader of Advanced Fuels, AIAA Associate Fellow 


$\begin{array}{ll}\text { NTP } & \text { Nuclear Thermal Propulsion } \\ \text { NTR } & \text { Nuclear Thermal Rocket } \\ \text { OC } & \text { Open cycle } \\ \text { O2 } & \text { Oxygen } \\ \text { PPB } & \text { Parts per billion }\end{array}$

\section{Introduction}

Human and robotic missions have been planned for targets throughout the solar system. Both types of missions can benefit greatly from the resources available from the planets and /or their moons (Refs. 1-15). These benefits include water on many of the outer planet moons and large asteroids. With this water, oxygen / hydrogen rocket propulsion systems can be fueled, breathing oxygen can be extracted, and other life support functions (cooling fluids, etc.) can be facilitated. In addition, the atmospheres of many planets have ready reserves of gases for propellant production. Carbon dioxide on Mars can be separated into oxygen and carbon monoxide or methane. The outer planets offer enormous amounts of energetic gases such as hydrogen, helium 3, methane, ethane, and ammonia. By using these in-situ resources, robotic precursor missions can double or triple their payloads to the surface and return double or triple the samples from the solar system targets. Without in-situ resource utilization (ISRU), solar system exploration will be exceedingly limited. For future large scale human missions, the possibilities of ISRU for of human exploration and finally settlement offer the best opportunities for sustainability and success.

\section{Human Exploration Options}

In the 1950's, 1960's, 1970's, and 1980's, ambitious robotic and human mission were planned, spanning from Mercury to the outermost reaches of the solar system (Refs. 1-15). While investments in robotic missions have continued, human exploration of the solar system has awaited new invigorating steps. While lunar and Mars missions are in the early step-wise planning stages, many cost barriers have prevented their implementation. Future human missions to other destinations such as Mercury and Saturn will also require long-term investments. Currently, Mercury and Saturn have robotic missions returning invaluable data on those planets and their environs (Refs. 16 to 20). These data have provided insights that will ensure the success of future missions. With its proximity to the Sun, Mercury has extremely high temperatures and requires special high heat flux considerations for long-term human visits or bases. In contrast, temperatures at Saturn and its moons require designs for cryogenic environments. The possibilities for in-situ resource utilization (ISRU) may allow more effective robotic missions and human visits to these planetary targets.

\section{A. Mercury}

Mercury is the closest planet to the Sun; ranging from a perihelion of 46 million $\mathrm{km}$ to an aphelion of nearly 70 million km. The high temperature, high heat flux environment at Mercury and the tenuous surface emanations of several major chemical species (sodium, etc.) surrounding it will likely pose challenges to long term human visits. Permanently shadowed craters offer a valuable niche for longer term human visits and planetary bases. Such craters offer cryogenic temperatures while the sun facing surface is at a temperature of 590 to 725 degrees $\mathrm{K}$. The north polar regions of Mercury have been identified as a likely location for such permanently shadowed craters (Ref. 16, 17, and 18). Water ice is also likely to be in these craters, further aiding and assisting any human explorations. Short 
exploratory missions can be accomplished with hopping ascent-descent vehicles from the base at the shadowed crater.

Reference 16 shows the locations of the shadowed craters. Reference 17 illustrates the temperatures that would exist in and near the craters: $80 \mathrm{~K}$ (in the shadowed area) to $350 \mathrm{~K}$ (at the edge of the sunlit region). The craters could accommodate a small base or at least an initial landing site. The lander's temperature could stay within the nominal operating temperatures of traditional spacecraft. The temperature distribution in the crater would allow construction of the base at the warmer side of the crater and then the frozen volatiles would be extracted with cryogenic mining machines. As it may be mixed with regolith and salts, additional purification of the water will be needed.

Additional potentially more complex issues may arise from Mercury's exosphere. The Mariner 10 and MESSENGER spacecraft have measured the planet's exosphere. Figures 1 and 2 (Ref. 22) provide some of the results of these investigations. Through meteoroid vaporization, ion sputtering, and photonstimulated desorption and thermal evaporation, sodium, calcium, and magnesium atoms are ejected from the surface. The tails of the ejected atoms extend over 33,600 km (21,000 miles) from Mercury. Over the long term, these and other ejected ions may have a deleterious effect on spacecraft surfaces.

Cryogenic cooling and storage of the hydrogen in orbit for the return trip will also be a challenge. Depots using sunshields and specialized radiators may enable this longer term storage. Figure 3 (Reference 21) provides a description of such cryogenic propellant depots for Earth orbital storage. Figure 4 presents the MESSENGER spacecraft configuration (Ref. 22). Reference 22 describes the cooling system for the MESSENGER spacecraft. A design combined both methods may be effective.

\section{B. Saturn and its moons}

Saturn is one of the outer planets. Its orbit has a perihelion 1,352.6 million km and an aphelion 1,514.50 million $\mathrm{km}$. An extensive series of flybys of the Saturnian moons have been conducted by the Cassini spacecraft. During these flybys, cameras and instruments capture and data on the moons' composition, atmosphere and cloud cover (on the moon Titan), volcanos, plumes, rotation, and gravity.

Titan is the largest moon of Saturn. Figure 5 shows the possible nature of Titan's interior, surface, and atmosphere (ref. 19). Its intriguing nature includes a nitrogen and methane atmosphere and a subsurface ocean (Ref. 4). Recent flybys of the Cassini spacecraft have shown direct visual evidence of the northern lakes. Large lakes in the northern polar regions are likely composed of liquid methane and ethane. Based on gravity measurements and theories of the evolution of Titan, a large ocean of water and ammonia may exist below the icy surface. With purification, the hopeful and likely water ocean can be an excellent supply of oxygen and hydrogen propellants. While methane and ethane in the lakes and atmosphere can be used as an effective chemical rocket propellants, its nitrogen could be used in cold gas propulsion or electric propulsion (resistojet, arcjet or magneto-plasma-dynamic (MPD) thrusters.

\section{Human Space Vehicles and Missions}

Space vehicle engine performance, propulsion mass scaling and delta- $\mathrm{V}$ estimates were used to predict the LEO masses of both Mercury and Saturn exploration vehicles. LEO mass estimates for extremely high energy missions were assessed. 


\section{A. Mercury Missions}

A human round trip mission to Mercury was assessed. The mission $\Delta \mathrm{V}$ values for the round trip Mercury missions were derived from the literature (Refs. 21 to 25). The highest $\Delta \mathrm{V}$ case was selected from this data: an Earth departure delta-V of $5.2 \mathrm{~km} / \mathrm{s}$, a Mercury arrival $\Delta \mathrm{V}$ 0f $10.9 \mathrm{~km} / \mathrm{s}$ and a Mercury departure $\Delta \mathrm{V}$ of $8.7 \mathrm{~km} / \mathrm{s}$ (Ref. 12). At Earth a capsule enters the atmosphere to return the crew directly to Earth (Ref. 12). The capsule's mass is 4,350 kg; the round trip time is 585 days with a 40-day stay time at Mercury. In this case, the vehicle does not land on Mercury (Ref. 12). The LEO masses of both chemical propulsion and nuclear thermal propulsion vehicles were estimated. Figure 12 compares the LEO masses for 2 types of chemical propulsion systems and 2 nuclear thermal propulsion (NTP) systems. The interplanetary chemical propulsion systems used tankage dry mass coefficients of $3 \%$ and $5 \%$ of the total propellant mass in the tankage. In many cases, these dry masses may be deemed to be optimistically low; however, they allow some relative comparison of the chemical propulsion and the nuclear mission cases.

The NTP vehicles dry mass was $15 \%$ of the propellant mass. In current NTP designs, an $\mathrm{I}_{\mathrm{sp}}$ of 900 seconds is nominally used. Somewhat lower $\mathrm{I}_{\mathrm{sp}}$ values were used for these missions: 800 and 850 seconds, respectively (Ref. 12). These lower $I_{s p}$ values were assumed given the high heat flux environment of Mercury and the degraded $\mathrm{I}_{\mathrm{sp}}$ values would reflect the added propellant used for propellant cooling and/or refrigeration. The chemical propulsion systems required between 17,150 MT and 31,230 MT to accomplish the mission. The NTP vehicles required approximately an order of magnitude less mass in LEO: 1,700 MT to 2,300 MT. Based on our prior analysis, the stage and lander mass was estimated with a mass scaling equation (Refs. 21 to 25).

$$
\mathrm{M}_{\text {dry,stage }}(\mathrm{kg})=\mathrm{M}_{\text {dry, coefficient }} \mathrm{M}_{\mathrm{p}}(\mathrm{kg})
$$

A Mercury landing vehicle mass was also estimated; the one-way $\Delta \mathrm{V}$ for the lander was $3.5 \mathrm{~km} / \mathrm{s}$. The ascent $\Delta \mathrm{V}$ was also $3.5 \mathrm{~km} / \mathrm{s}$ (Ref. 22). These $\Delta \mathrm{V}$ values accommodate approximately $19 \%$ for gravity losses for each maneuver; this gravity loss $\Delta \mathrm{V}$ is added to the orbital velocity for a $100 \mathrm{~km}$ orbit which is $2.945 \mathrm{~km} / \mathrm{s}$. The lander $\mathrm{I}_{\mathrm{sp}}$ was 480 seconds. The higher $\mathrm{I}_{\mathrm{sp}}$ was chosen for the lander as the engine used a higher engine expansion ratio that the interplanetary transfer vehicle. The smaller engine size would allow a higher expansion ratio, given the typical volume constraints for space vehicles. The dry mass coefficient was $20 \%$ of the total propellant load. While the Mercury missions will likely require more aggressive thermal control (propellant shielding, cooling, etc.), that thermal control system mass is accommodated in the payload mass of the vehicle. The payload delivered to the surface was 10 MT. Figure 13 compares the mass in LEO of a one-way lander and a round trip lander. The masses were 140 MT for the round trip lander and 27 MT for the one-way lander. Thus, using ISRU on the surface of Mercury to replenish the lander's propellant would allow a savings of 113 MT on this mission. Additional analyses are needed to investigate the mass reductions for the interplanetary transfer vehicle to carry the lander to Mercury. Another option would be to carry 5 landers to Mercury rather than carry simply one lander; many more permanently shadowed craters could then be visited on one mission. The interplanetary vehicle carrying the 5 landers could be sent on a lower energy trajectory than the human flights, thus saving additional mass launched into LEO in the overall Mercury architecture.

Using Mercury resources to augment the human missions was investigated. An ISRU system's effect on reducing the LEO mass (see Table 6 for details) was analyzed. For the NTP-1 and NTP-2 systems, cases were computed where the Mercury departure $\Delta \mathrm{V}$ propellant was supplied at Mercury. The Mercury departure stage is brought from Earth with no propellant. Hydrogen would be produced from the water at the northern polar craters, and transported to orbit. For the NTP-1 case, 94 MT of hydrogen would be transported to orbit. With NTP-2, the propellant mass required in Mercury orbit is 82 MT. With the in-situ hydrogen production, the LEO mass of the NTP-1 case is reduced from 2300 MT to 760 MT, 
as shown in Figure 12. Similar large LEO mass reductions are enabled for the NTP-2 system; using ISRU, the 1667 MT LEO mass is reduced to $588 \mathrm{MT}$.

Table 1. Space Vehicle Dry Mass Coefficient and Rocket Engine Specific Impulse ( $\left.\mathrm{I}_{\mathrm{sp}}\right)$

\begin{tabular}{|l|c|c|}
\hline \multicolumn{1}{|c|}{ Technology } & $\mathbf{I}_{\mathbf{s p}}$ (sec) & $\mathbf{M}_{\text {dry,coefficient }}(\mathbf{k g} / \mathbf{k g ~ M p )}$ \\
\hline Chemical-1 & 450 & 0.03 \\
\hline Chemical-2 & 450 & 0.05 \\
\hline Chemical lander & 450 & 0.20 \\
\hline NTP-1 & 800 & 0.15 \\
\hline NTP-2 & 850 & 0.15 \\
\hline
\end{tabular}

\section{B. Mercury surface excursion planning}

While the temperature is quite comfortable for human habitation inside the permanently shadowed craters (PSC), excursions will be desirable to other locations. While the temperature can be quite high outside the PSC, short excursion will be possible. Robotic missions with cooling systems can persist for long periods in the sunlit areas. These explorers can provided data on the most attractive locations for sampling, and the need for human exploration. Cooling systems based on the heat pipe based design from MESSENGER can be effective (Ref. 22).

Hopping out of permanently shadowed craters for short periods. Hopper spacecraft have been conceived for many planetary missions (Ref. 24). While the hoppers can be used for excursions outside the PSC, flights into the anti-Sun shadowed regions of the Mercury will allow for more extensive planet wide exploration (or in essence, wait until it is night time).

\section{Jupiter and Saturn mission studies and results}

Human Jupiter and Saturn mission analyses using nuclear pulse propulsion were conducted in the 1960's and 1970's (Ref. 13, 14, 15). Small nuclear devices were detonated behind the vehicle and with a combination of many 100's of nuclear devices, a massive pusher plate and shock absorbers, the vehicle is accelerated through the needed delta- $\mathrm{V}$. The LEO masses for varying propulsion dry masses and total mission delta-V assumptions were estimated. These missions used propulsion mass scaling that may have been optimistic. Parametric variation of the dry mass was analyzed.

The Reference 13, 14 and 15 work provided the details from which the propulsion system mass scaling equations were derived. The A parameter of 358,000 is the mass of the pusher plate and associated shock absorbers for the 20 -meter diameter system. The 20 -meter diameter system design was used on the outer planet mission analyses conducted in Refs. 14 and 15. The Saturn and the Jupiter 
mission studies used the same set of propulsion mass scaling equations. The Saturn mission delta-V values were derived from Refs. 13, 14 and 15.

The mass scaling equation was:

$\operatorname{Mdry}(\mathrm{kg})=$ A + B Mp

where

Mdry = Propulsion system dry mass (kg)

$\mathrm{Mp}=$ Propellant mass $(\mathrm{kg})$

A = fixed propulsion system mass $(\mathrm{kg})$

$\mathrm{B}=$ propellant mass dependent mass $(\mathrm{kg} / \mathrm{kg} \mathrm{Mp})$

The final set of mass scaling equations were:

$\operatorname{Mdry}(\mathrm{kg})=358,000+0.01 \mathrm{Mp}$

Also the parameter $\mathrm{B}$ was also varied over a range of values: $\mathrm{B}=0.01,0.02,0.05$ and 0.10 .

The NPP space vehicle Isp was 3,000 seconds. While a 3,150 second Isp was used in Ref. 13 and 14, the lower (and more conservative) 3,000 second value was used in later publication (Ref. 15).

\section{Jupiter mission design and payload}

Jupiter missions were designed to depart LEO, arrive at Jupiter and enter orbit about Callisto (a large Jupiter moon), remain in orbit for 30 to 50 days, depart Jupiter and Callisto and return to LEO. In Refs. 13, 14, and 15, the vehicle delivered a payload of 302 MT to Callisto. The crew size was 20 persons and 2 Jupiter moon landers were carried.

Appendix B summarizes the baseline Jupiter mission results. Figure B1 illustrates the LEO masses of several Jupiter missions. Table B1 provides the overall delta-V summary for the 5,920 MT case (for a delta-V of $60 \mathrm{~km} / \mathrm{s}$ ). This LEO mass was one of the highest masses of all Jupiter mission NPP vehicle designs. Table B2 summarizes many other Jupiter mission designs. Lower delta-V cases were also conducted and the lowest delta- $\mathrm{V}$ of $20 \mathrm{~km} / \mathrm{s}$ represented a LEO mass of nearly 1,500 MT. A series of low and high delta-V missions are summarized in Figures B2 and B3.

\section{E. Saturn missions}

Figures 9 through 16 provide the mass estimates for a series of Saturn missions over a range of mission delta-V. Based on the work of Ref. 13, 14, 15, and 26, a range of mission delta-V from $60 \mathrm{~km} / \mathrm{s}$ to $120 \mathrm{~km} / \mathrm{s}$ was used in the calculations. While the highest delta- $\mathrm{V}$ values may represent impractically high LEO masses for some space missions, they are presented for comparison and completeness. The same overall mission payload masses were used for human Jupiter and Saturn missions 
Figures 9 to 16 show the variations in LEO mass for B coefficients of 0.01, 0.02, 0.05, and 0.1. The variation in B coefficient would reflect the variation in the mass of the feed systems required for nuclear unit storage, transfer, and ejection. Reference 26 noted that the B coefficient would likely be 0.01. However, this mass could easily increase given the complexity of the feed systems and the need for multiple canisters to store the individual nuclear units. Each canister was designed to hold 100's of nuclear units.

For vehicles delivering a delta-V of $60 \mathrm{~km} / \mathrm{s}$, the LEO masses were 6,000 MT for the case of $\mathrm{B}=0.01$ to $7600 \mathrm{MT}$ for a $\mathrm{B}=0.10$. In many cases, space vehicles experience mass growth during development. As such, a more conservative mass estimate is always good for comparison. The vehicle masses for the highest delta-V cases are over 48,000 MT to 97,000 T. These LEO masses are unusually high and will require many specialized heavy lift launch vehicles. Reference 30 noted the development of the NEXUS vehicle, a post Saturn V capability of over 450 MT (nearly 1 million lbm) into LEO. Reference 30 noted the need for a NEXUS launch capability of 4 to 8 times that of the Saturn V (implying up to nearly 1,000 MT into orbit). Certainly, high Isp options using fusion propulsion for the interplanetary vehicle would simplify operations and reduce the number of launches to LEO.

Even with an increase launch capability, the number of 1,000 MT payload launches required would likely be higher than 50 . This number would also include cryogenic boiloff makeup (for propulsion, life support, science support, etc.), airborne support equipment, and other contingency masses.

\section{Observations}

Saturn mission data was derived from several historical sources, detailing ambitious human missions. While on-orbit assembly of these more massive vehicles (of over 10,000 MT) is not impossible, it would seem likely that other higher Isp propulsion options would be more attractive. Nuclear electric with hundreds of megawatts or nuclear fusion designs could deliver Isp values of 10,000 to 30,000 seconds (Ref. 31).

\section{Concluding Remarks}

Propulsion systems for human missions to Mercury and Saturn were assessed. While there are many thermal challenges with the Mercury environment, the potential of permanently shadowed craters in the northern polar region can provide a safe haven with cool temperatures for human landings and habitation. Nuclear thermal propulsion (NTP) without ISRU can enable round trip human Mercury missions for a LEO mass of 1,700 to 2,300 MT. Using hydrogen produced on Mercury, an ISRU mission can reduce that LEO mass to 590 to 760 MT, respectively. Landers using only Earth based oxygen/hydrogen can land $10 \mathrm{MT}$ on the surface and return $10 \mathrm{MT}$ to orbit. With Mercury ISRU, 5 landers can be delivered to Mercury on one NTP mission, each carrying 10 MT on round trip flights.

Saturn missions may require a LEO mass of at least 6,000 MT for a mission delta-V of $60 \mathrm{~km} / \mathrm{s}$. Missions with up to $120 \mathrm{~km} / \mathrm{s}$ delta-V were analyzed. While LEO masses of 10,000 to 100,000 MT and more are needed for such missions, larger future space operations may be able to accommodate such massive vehicles. Due to the relative frailty of the human body (subject to deep space radiation and lower gravity), fast mission to the outer planets will be required. Ambitious space missions using higher energy propulsion will be needed to enable such high speeds. Investments in higher energy nuclear thermal propulsion would be the first best step. Incremental investments in more advanced propulsion system will benefit not only human and robotic missions, but many benefits will be gleaned in numerous 
other technological areas. These technological innovations will enable Krafft Ehricke's vision of a polyglobal civilization, which will indeed benefit all of humanity and all of its endeavors.

\section{References}

${ }^{1}$ Ehricke, K. A., "Lunar industrialization and settlement - Birth of poly-global civilization," Lunar Bases and Space Activities of the 21st Century Conference, Houston, TX, Lunar and Planetary Institute, 1985, p. 827-855.

${ }^{2}$ Ehricke, K. A., "Harenodynamic cooling - The use of lunar sand as cooling medium," Acta Astronautica, Vol. 11, June 1984, p. 319-325.

${ }^{3}$ Ehricke, K. A., "Profitability of manufacturing in space in view of lunar industrial development and geo-socio-economic benefits," Manufacturing in space; Proceedings of the Winter Annual Meeting, Boston, MA, November 13-18, 1983, American Society of Mechanical Engineers, 1983, p. 183-198.

${ }^{4}$ Ehricke, K. A., "A socio-economic evaluation of the lunar environment and resources. III Selenospheric economics and cislunar/terrestrial market analysis," IAF PAPER 82-235, International Astronautical Federation, International Astronautical Congress, 33rd, Paris, France, Sept. 27-Oct. 2, 1982, $25 \mathrm{p}$.

${ }^{5}$ Ehricke, K. A., "A socio-economic evaluation of the lunar environment and resources. II Energy for the selenosphere," IAF PAPER 79-A-16, International Astronautical Federation, International Astronautical Congress, 30th, Munich, West Germany, Sept. 17-22, 1979, 25 p.

${ }^{6}$ Krafft A. Ehricke, A socio-economic evaluation of the lunar environment and resources: I. Principles and overall system strategy," Acta Astronautica, Volume 8, Issues 11-12, NovemberDecember 1981, Pages 1389-1405.

${ }^{7}$ Ehricke, K., "Lunar industries and their value for the human environment on Earth." Acta Astronautica, 1974. Volume 1, pp. 585-622.

${ }^{8}$ Ehricke, K. "Further analyses of the slide lander and of drop delivery systems for improved lunar surface access," Acta Astronautica Volume 10, Number 9, pp. 629 to 650, 1983.

${ }^{9}$ Ehricke, K. A., "Economy of large launch vehicles including orbital labor cost," AIAA 1963277.

${ }^{10}$ Ehricke, K., "A comparison of propellants and working fluids for rocket propulsion," American Rocket Society (ARS) Journal, September-October 1953, Volume 23, Number 5, pp. 287-300.

${ }^{12}$ Manning, L. "Comparison of Several Trajectory Modes for Manned and Unmanned Missions to Mercury 1980-2000,” AIAA 67-28, 1967.

${ }^{13}$ Marx, G., "Model study of fuel requirements for fast interplanetary flights using advanced nuclear propulsion systems and refueling at destination," Thesis, Technical University of Berlin (West Germany), In German, May 9, 1967.

${ }^{14} \mathrm{~K}$. EHRICKE, "STUDY OF INTERPLANETARY MISSIONS TO MERCURY THROUGH SATURN WITH EMPHASIS ON MANNED MISSIONS TO VENUS AND MARS 1973/82 INVOLVING CAPTURE," Engineering Problems of Manned Interplanetary Exploration, 1963, AIAA 1963-1514 . 
${ }^{15}$ Ehricke, K., Perspective and Systems Engineering of Manned Planetary Flight,” AAS 70-037, 1970. In: Space Shuttles and Interplanetary Flight, Volume 28, Advances in Astronautical Sciences, 1970.

MESSENGER at Mercury:

${ }^{16}$ David J. Lawrence et al., "Evidence for Water Ice Near Mercury's North Pole from MESSENGER Neutron Spectrometer Measurements.” Science 339, 292 (2013);

${ }^{17}$ IMAGING INSIDE MERCURY'S PERMANENTLY SHADOWED CRATERS - FIRST IMAGES FROM MESSENGER (Chabot, N.), Paper 1693, 44th Lunar and Planetary Science Conference (2013).

${ }^{18}$ MESSENGER Planetary Conference Multimedia Page - David A. Paige, MESSENGER Participating Scientist, University of California, Los Angeles, CA. http://messenger.jhuapl.edu/news_room/presscon12_multi.html . with: David A. Paige, et al., "Thermal Stability of Volatiles in the North Polar Region of Mercury," Science, January 18, 2013: Vol. 339, No. 6117, pp. 300-303.

Cassini at Saturn:

${ }^{19}$ G. TOBIE, J.I. LUNINE, J. MONTEUX, O. MOUSIS AND F. NIMMO, “The Origin and Evolution of Titan," in Titan: Interior, Surface, Atmosphere and Space Environment Muller-Wodarg, Griffith, Lellouch and Cravens, eds., Cambridge Univ Press, pp. 24-50, 2012.

http://www.es.ucsc.edu/ fnimmo/website/Tobie_Titan.pdf .

${ }^{20}$ Enceladus: An active ice world in the Saturn System J.R. Spencer, F. Nimmo, Annual Review of Earth and Planetary Sciences 41, 693-717, 2013.

Mercury mission design:

21 "Cryogenic Propellant Depots Design Concepts and Risk Reduction Activities," Future InSpace Operations (FISO), teleconference, March 2, 2011, Christopher McLean, 303-939-713, cmclean@ball.com and http://spirit.as.utexas.edu/ fiso/archivelist.htm .

${ }^{22}$ MESSENGER - Mercury Orbit Insertion (MOI) Press Kit, NASA Headquarters and the Applied Physics Laboratory, Johns Hopkins University, March 2011, http://messenger.jhuapl.edu, http://messenger.jhuapl.edu/news room/Mercury_PK TST Rev7 Web.pdf .

Titan:

${ }^{23}$ Fulchignoni, M., et al. "In situ measurements of the physical characteristics of Titan's environment” Nature 438, pp. 785-791, December 8, 2005.

Hopper:

${ }^{24}$ Linne, Diane L., Barsi, Stephen J., Sjauw En Wa, Waldy K., Landis, Geoffrey A., "Mars Surface Mobility Leading to Sustainable Exploration," AIAA Paper 2012-0806, January 2012. 
Space vehicles:

${ }^{21}$ Palaszewski, B., "Metallized Propellants for the Human Exploration of Mars ," NASA-Lewis Research Center, NASA TP-3062, presented at the Case For Mars IV Conference, Boulder, CO, June 48 1990. Also in the AIAA Journal of Propulsion and Power, Vol. 8, No. 6, Nov.-Dec. 1992, pp. 11921199

22 Bensky, M., "Propulsion requirements for soft landing in extraterrestrial environments," Rocketdyne, NAS7-124, NASA CR-55088, February 1963.

${ }^{23}$ Palaszewski, B., "Atmospheric Mining in the Outer Solar System: Resource Capturing, Storage, and Utilization," AIAA 2012-3742, July 2012.

${ }^{24}$ Palaszewski, B., "Atmospheric Mining in the Outer Solar System: Issues and Challenges for Mining Vehicle Propulsion,” AIAA 2011-6041, August 2011.

${ }^{25}$ Palaszewski, B., "Lunar Missions Using Advanced Chemical Propulsion: System Design Issues," NASA-Lewis Research Center, NASA TP-3065, AIAA 90-2341, presented at the 26th AIAA/ASME/SAE Joint Propulsion Conference, Orlando, FL, July, 1990, also in AIAA Journal of Spacecraft and Rockets, Vol. 31, No. 3, May-June 1994, pp. 458-465.

Nuclear pulse propulsion:

26 "Interplanetary maneuvers in manned helionautical missions," (Ehricke, 1965) AIAA 1965695.

${ }^{27}$ Ehricke, K. A.," Solar Transportation," Presented to the 4th Goddard Memorial Symposium, AM. ASTRONAUTICAL SOC., WASHINGTON, D. C., 15-16 MAR. 1966

28 "A Grand Vision of Man's Role In Colonizing the Universe" by Oyang Teng, LaRouche Youth Movement (Book review) - Marsha Freeman, "Krafft Ehricke's Moon: The Extraterrestrial Imperative," Technology Editor of Executive Intelligence Review, 2009.

http://www.21stcenturysciencetech.com/Articles_2009/Summer-2009/Extraterrestrial_Imperative.pdf

${ }^{29}$ G. R. Schmidt, J. A. Bonometti, and C. A. Irvine, "Project Orion and Future Prospects for Nuclear Pulse Propulsion," JOURNAL OF PROPULSION AND POWER, Vol. 18, No. 3, May-June 2002.

30 “NEXUS - CONCEPT OF A LARGE REUSABLE LAUNCH VEHICLE," (Krafft Ehricke, and FREEMAN D'VINCENT), AIAA 1963-277, 1963.

${ }^{31}$ Williams, Craig H.; Dudzinski, Leonard A.; Borowski, Stanley K.; Juhasz, Albert J., "Realizing "2001: A Space Odyssey": Piloted Spherical Torus Nuclear Fusion Propulsion,” NASA/TM2005-213559, AIAA Paper 2001-3805, published 2005 


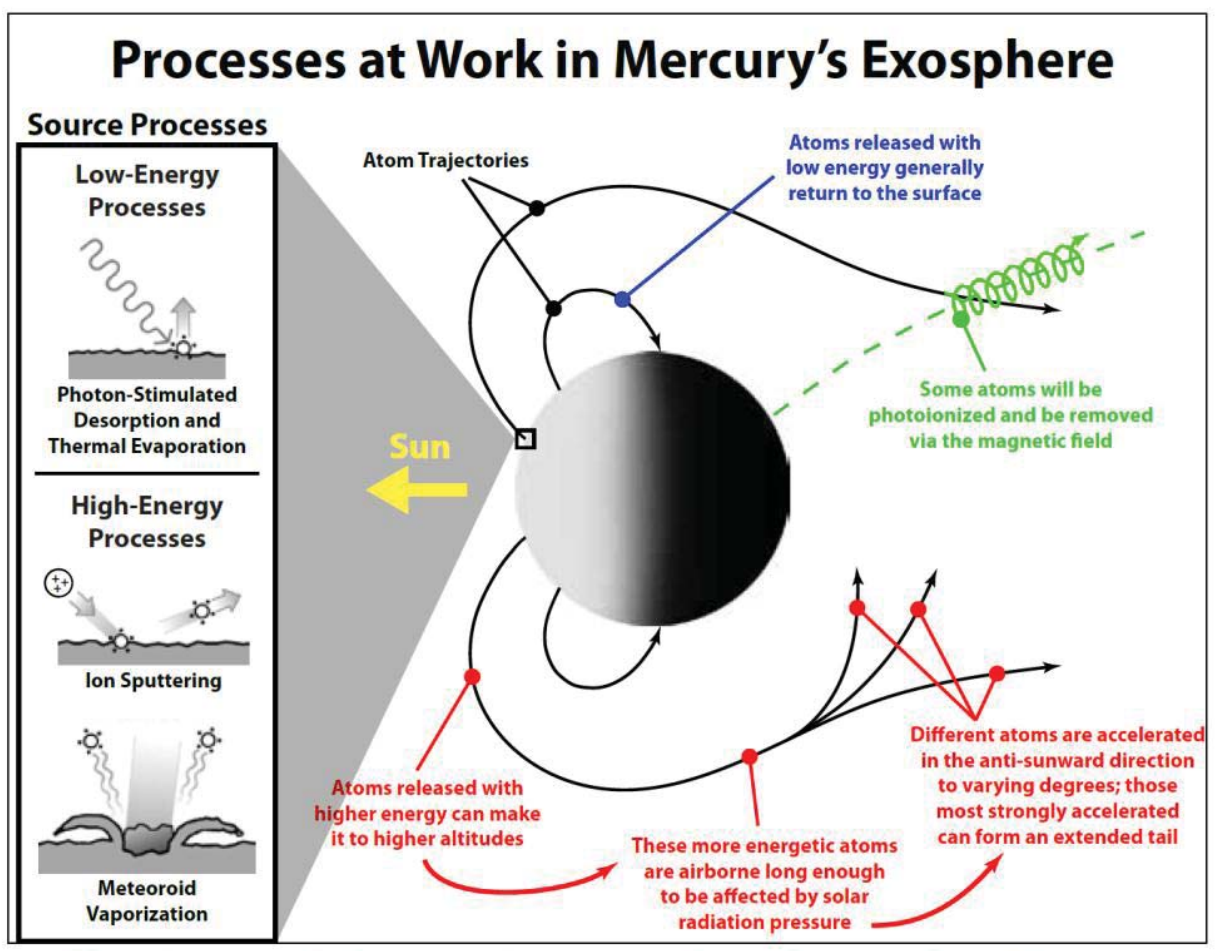

Schematic summary of the processes that generate and maintain the exosphere of Mercury.

Figure 1. Processes at work in Mercury's Exosphere (Ref. 22)

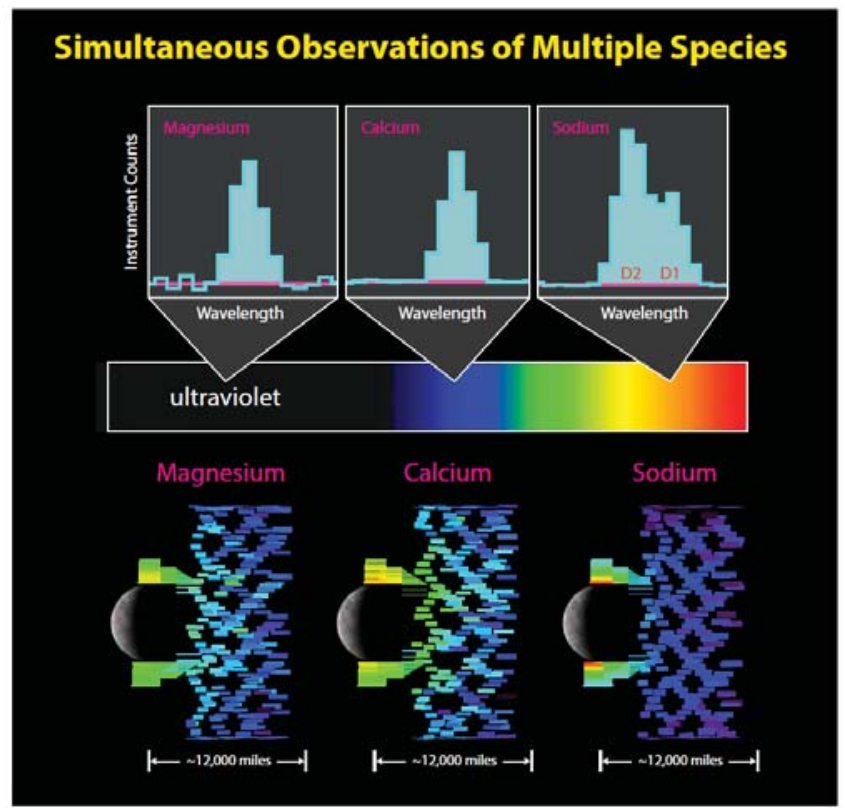

Figure 2. Elements emanating from Mercury due to solar flux (Ref. 22). 


\section{Ball Simple Depot Extensibility to Larger Depots}

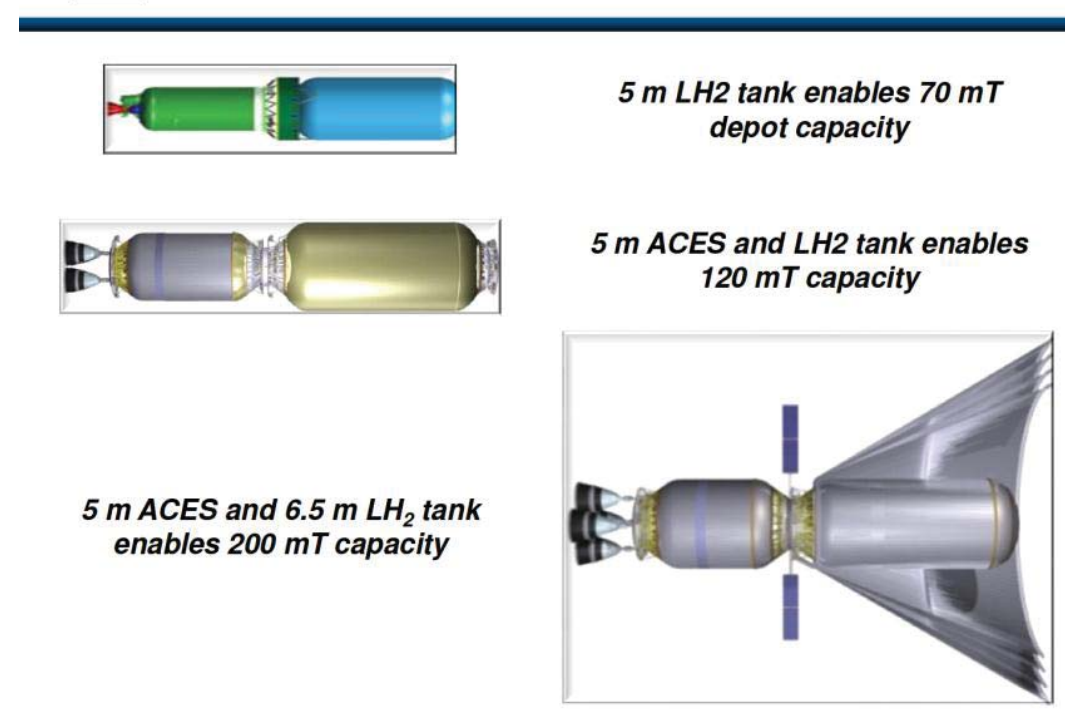

Page_15

Figure 3. Cryogenic propellant depot options (Ref. 21, "Cryogenic Propellant Depots Design Concepts and Risk Reduction Activities," Future In-Space Operations (FISO), teleconference, March 2, 2011, Christopher McLean (Ball Aerospace).

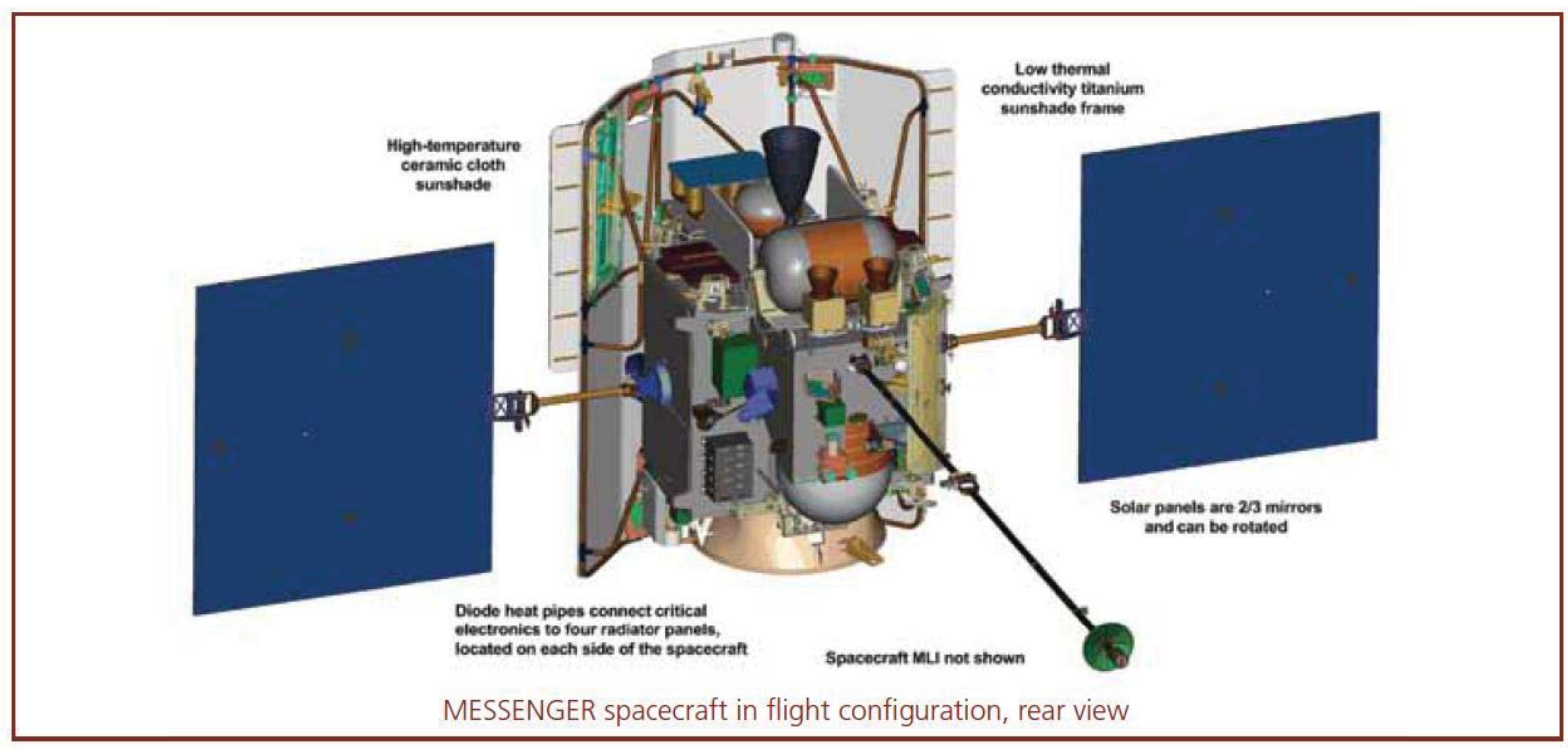

Figure 4 MESSENGER spacecraft configuration (Ref. 22) 


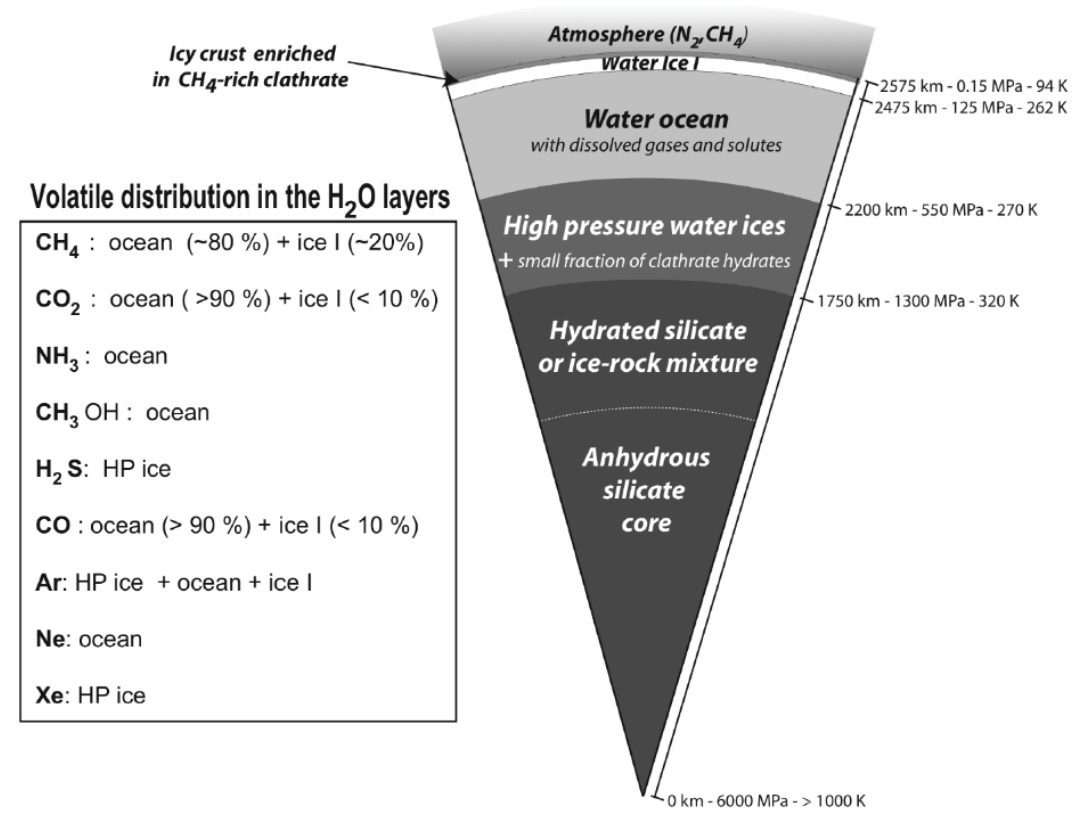

Figure 5. Possible present day cross section of Titan (Ref. 14).

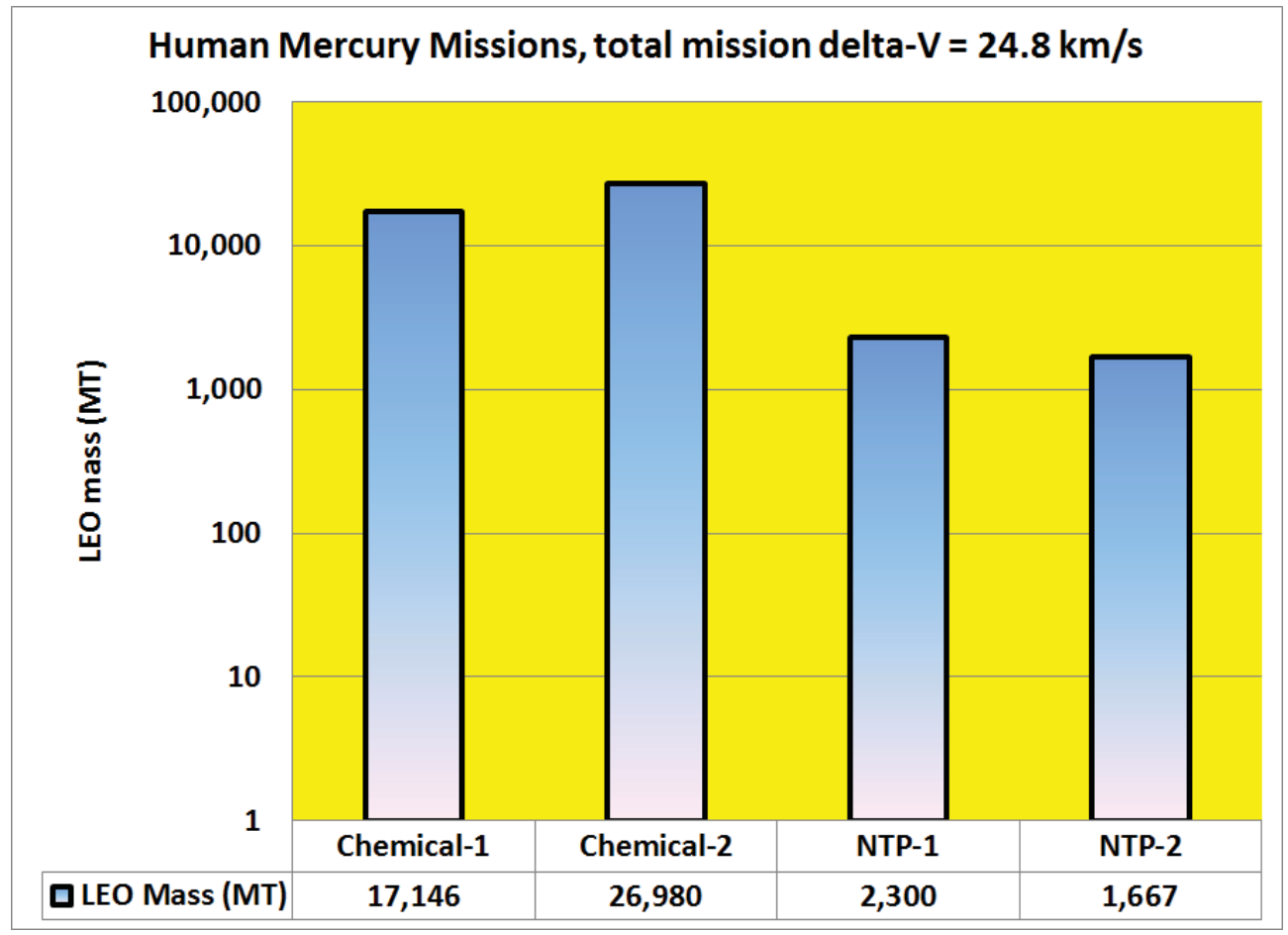

Figure 6. LEO Departure Mass for Human Mercury Missions 


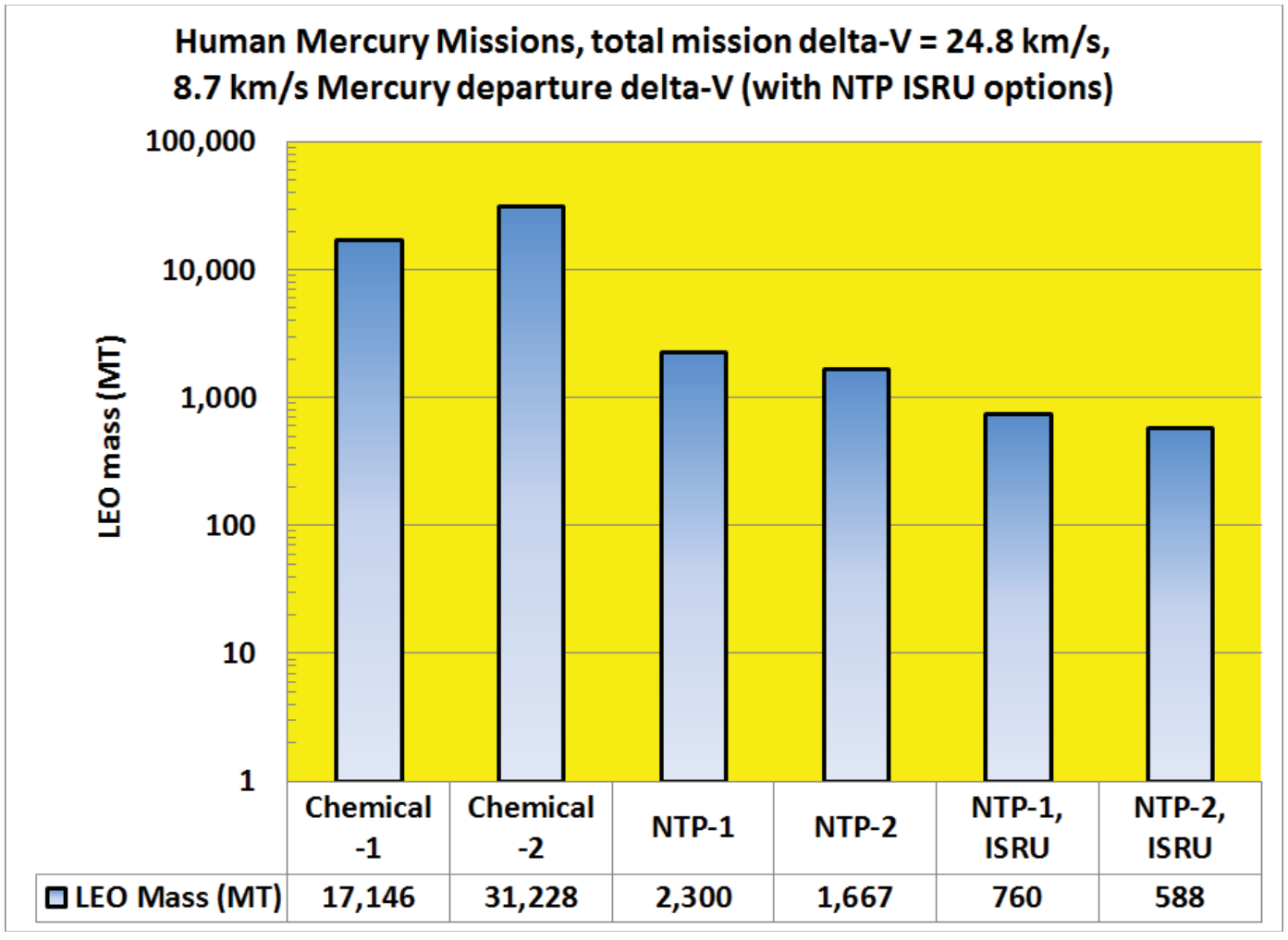

Figure 7. LEO masses of human round trip missions to Mercury (without and with ISRU)

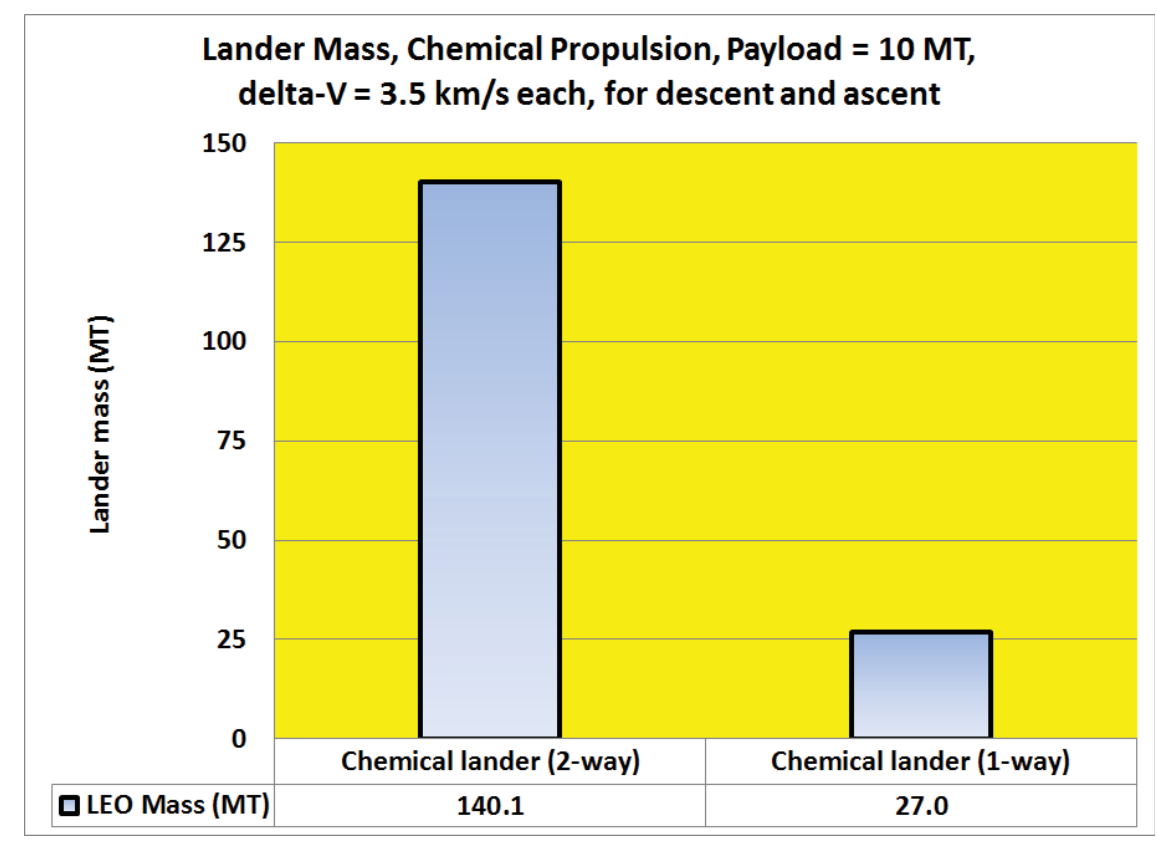

Figure 8. Mercury Lander Mass (2-way (without ISRU) and 1-way (ISRU)) 


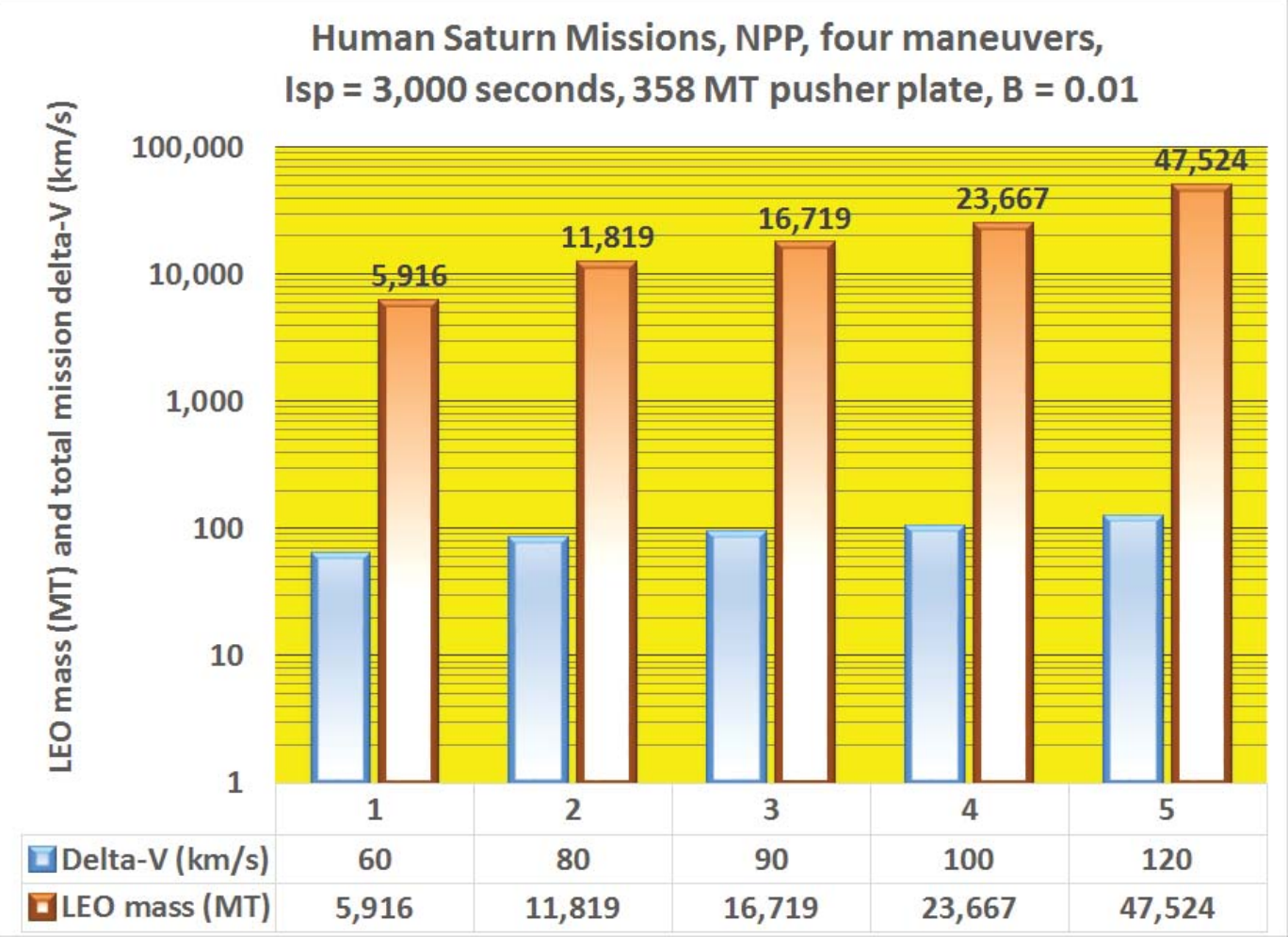

Figure 9. Saturn mission data, $\mathrm{B}=0.01 \mathrm{Mp}$

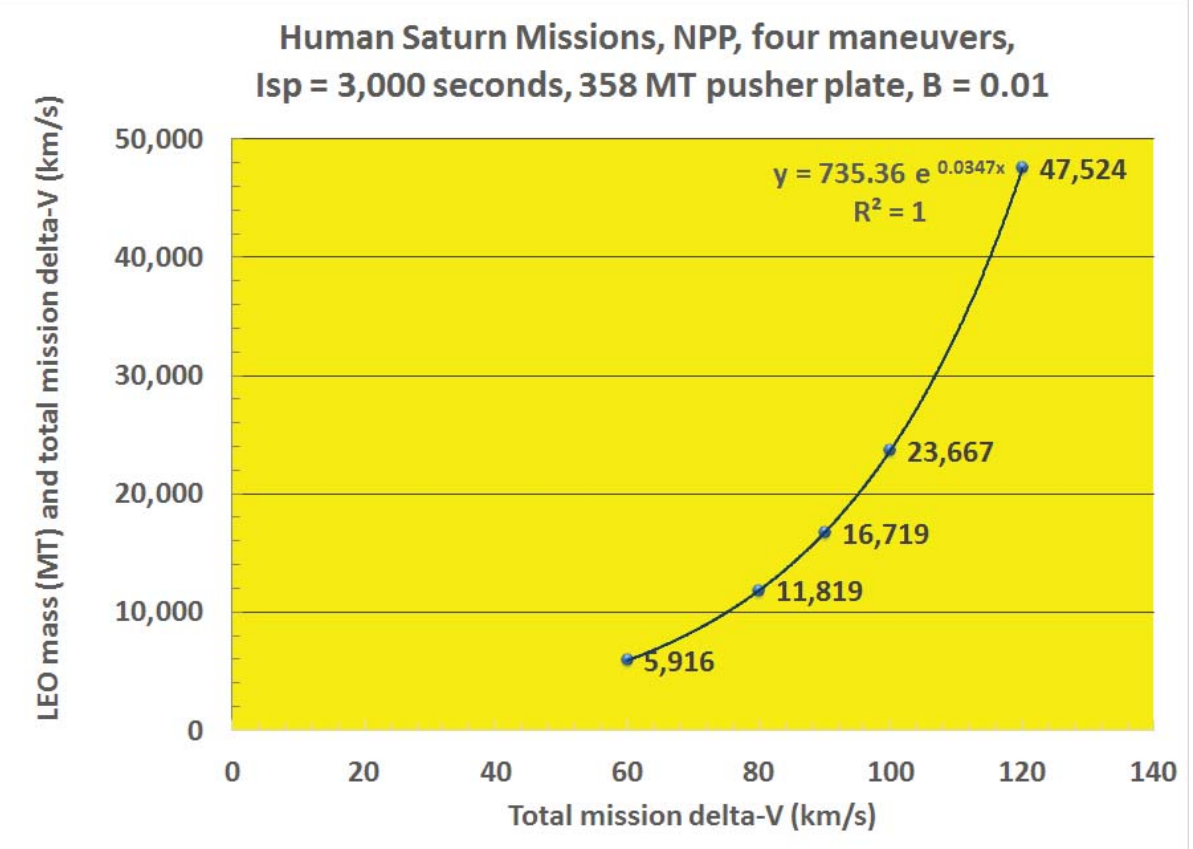

Figure 10. Saturn mission data, correlation, $\mathrm{B}=0.01 \mathrm{Mp}$ 


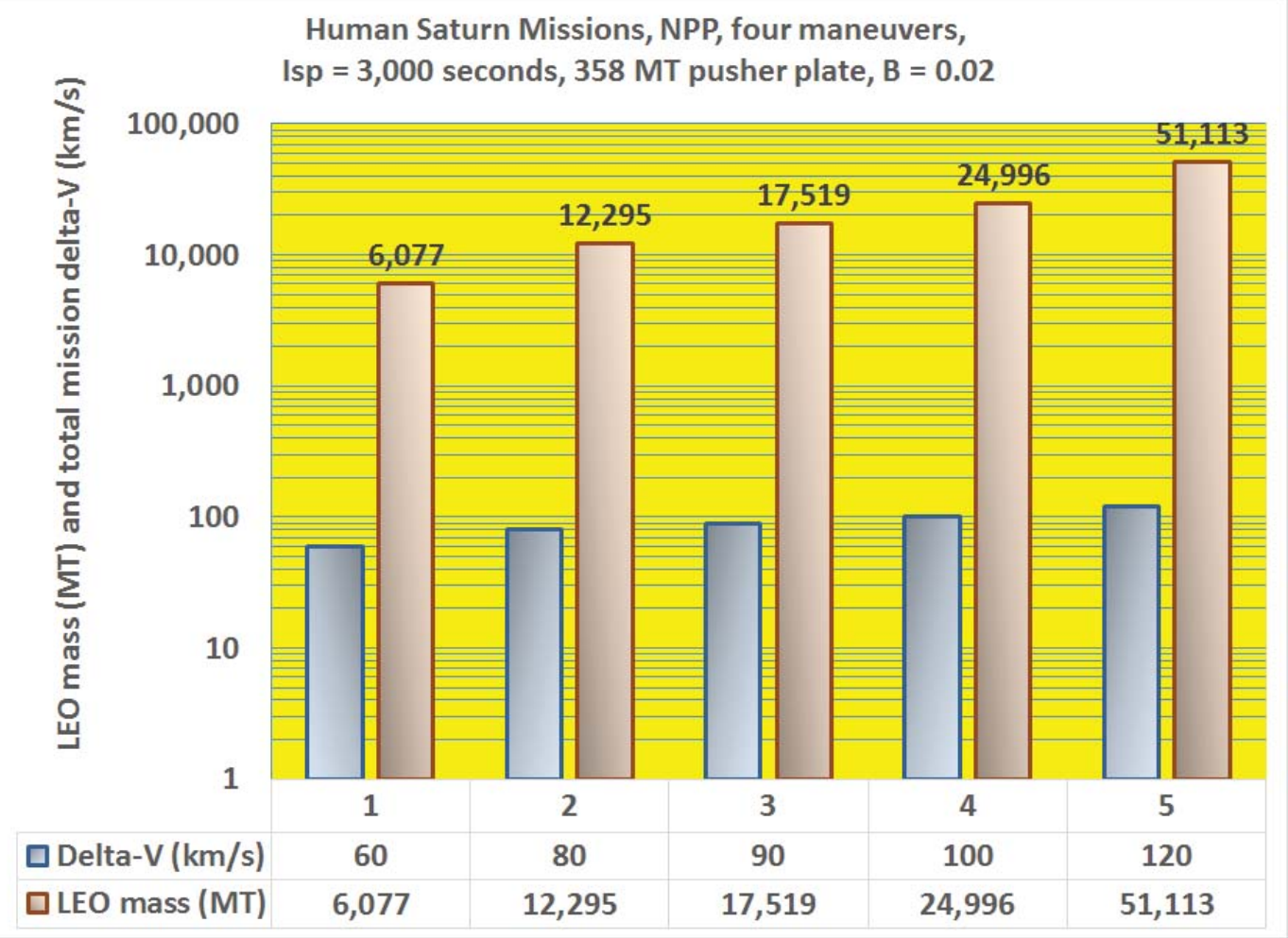

Figure 11. Saturn mission data, B = $0.02 \mathrm{Mp}$

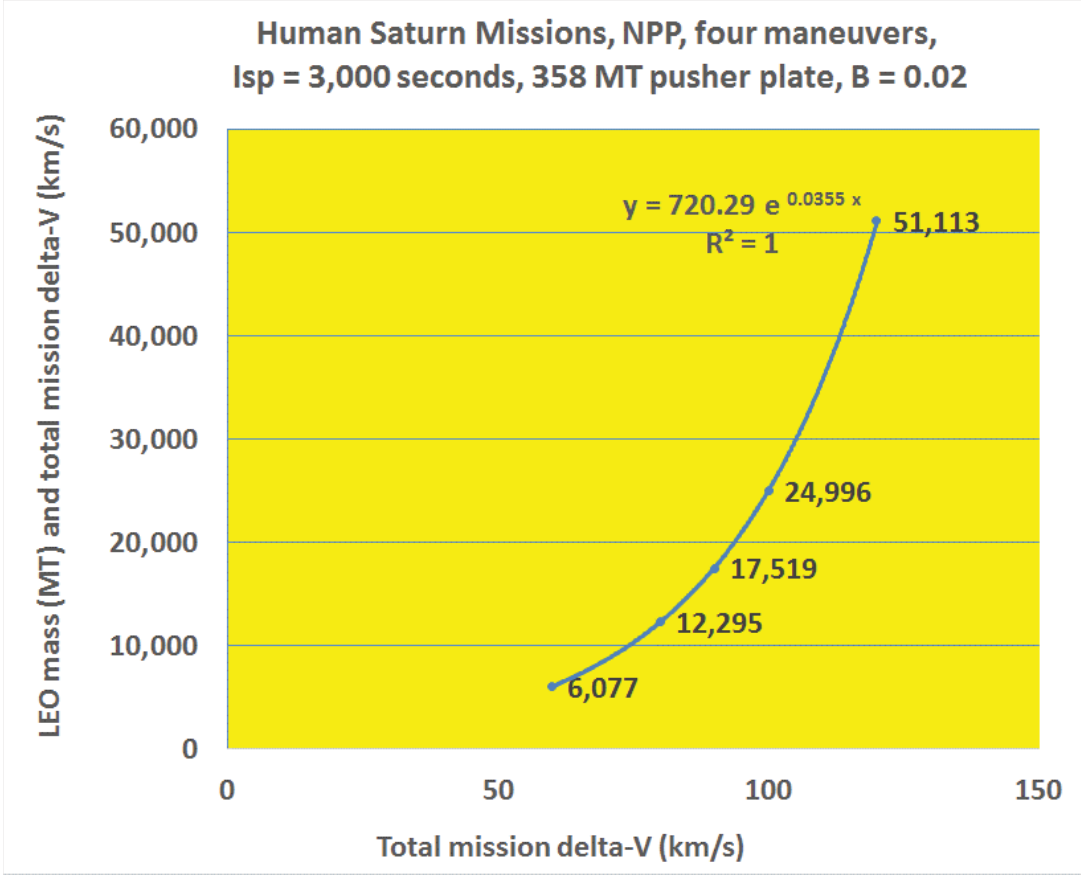

Figure 12. Saturn mission data, correlation, B = 0.02 Mp 


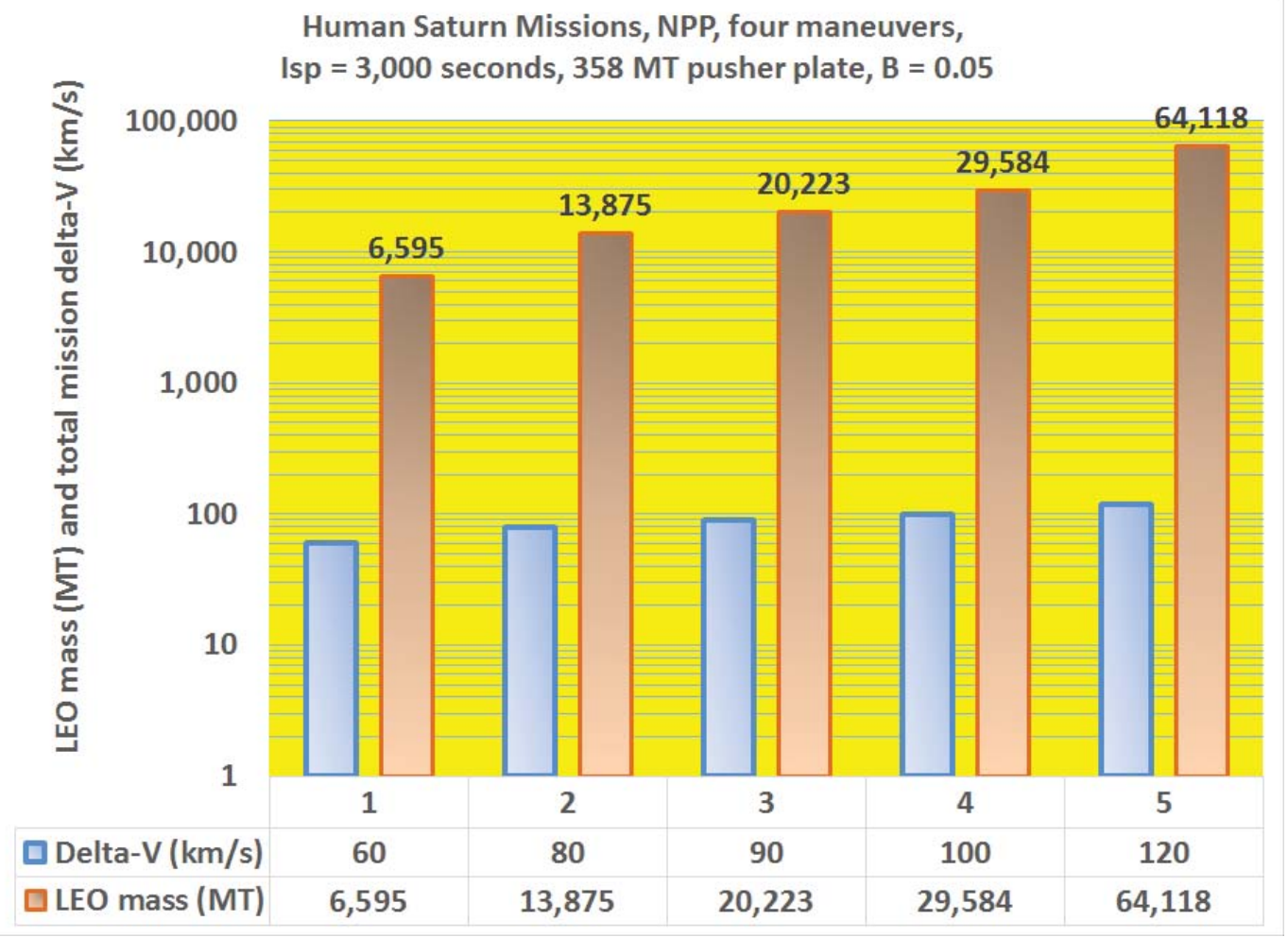

Figure 13. Saturn mission data, $\mathrm{B}=0.05 \mathrm{Mp}$

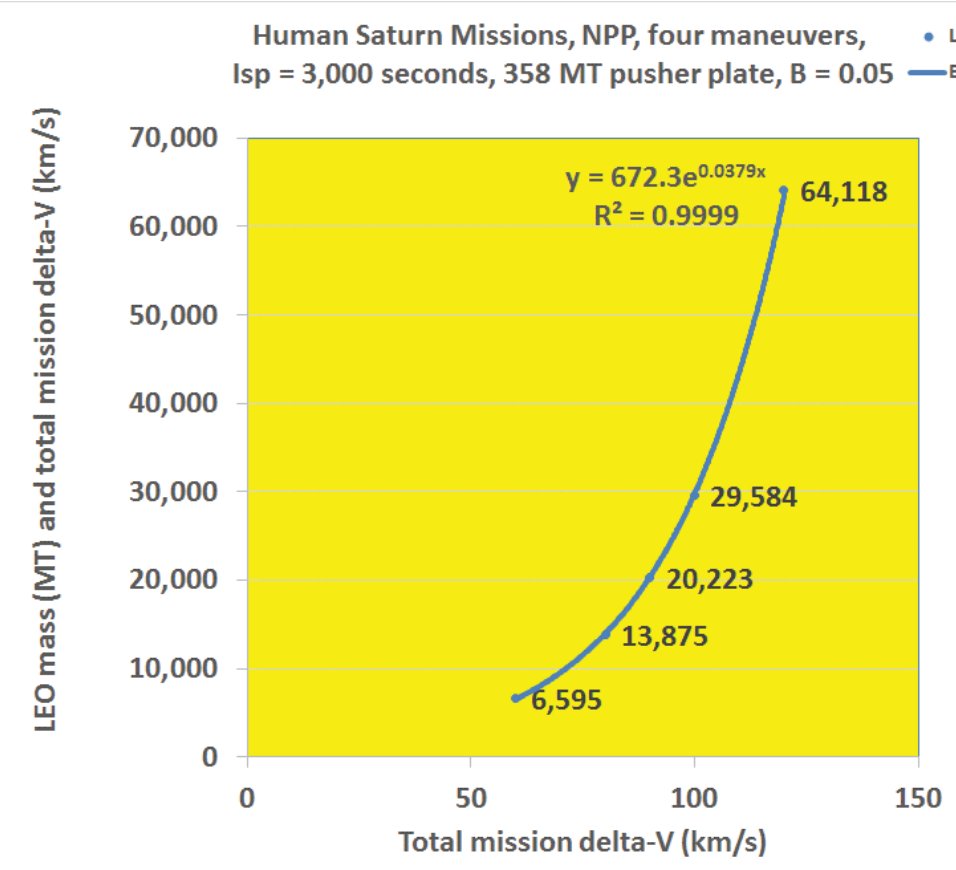

Figure 14. Saturn mission data, correlation, $\mathrm{B}=0.05 \mathrm{M}$ 


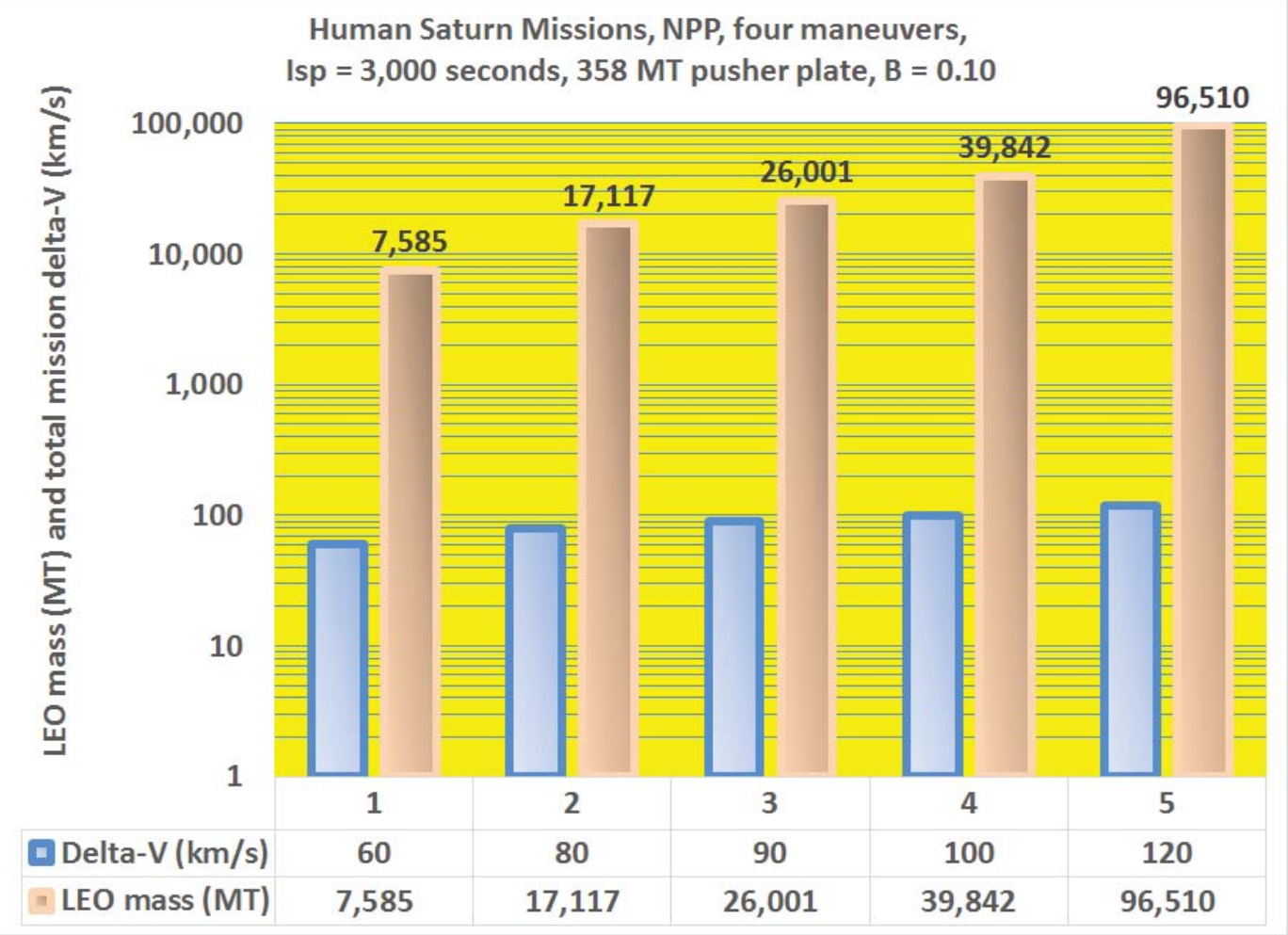

Figure 15. Saturn mission data, B $=0.10 \mathrm{Mp}$

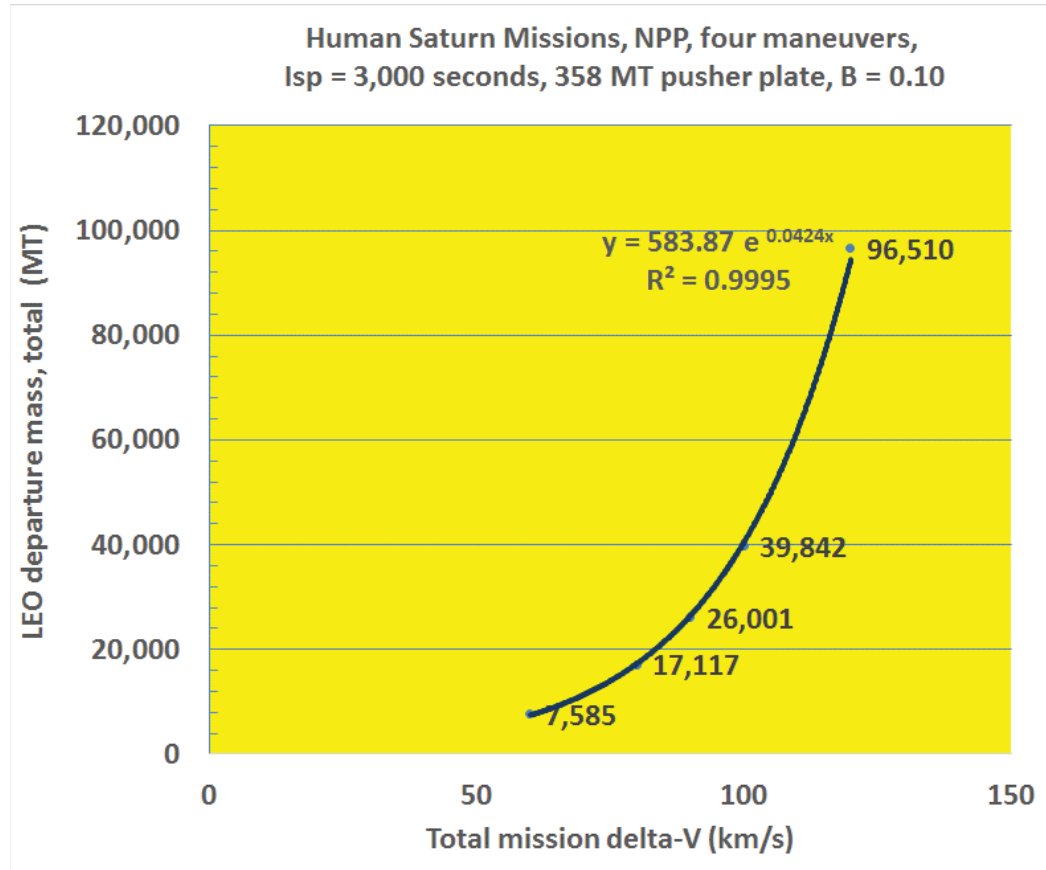

Figure 16. Saturn mission data, correlation, $\mathrm{B}=0.10 \mathrm{Mp}$ 
Appendix A: Titan's atmospheric temperature, pressure and density (Ref. 23)

Chart created from data in: Fulchignoni, M., et al. "In situ measurements of the physical characteristics of Titan's environment”, Nature 438, 785-791, 8 December, 2005.

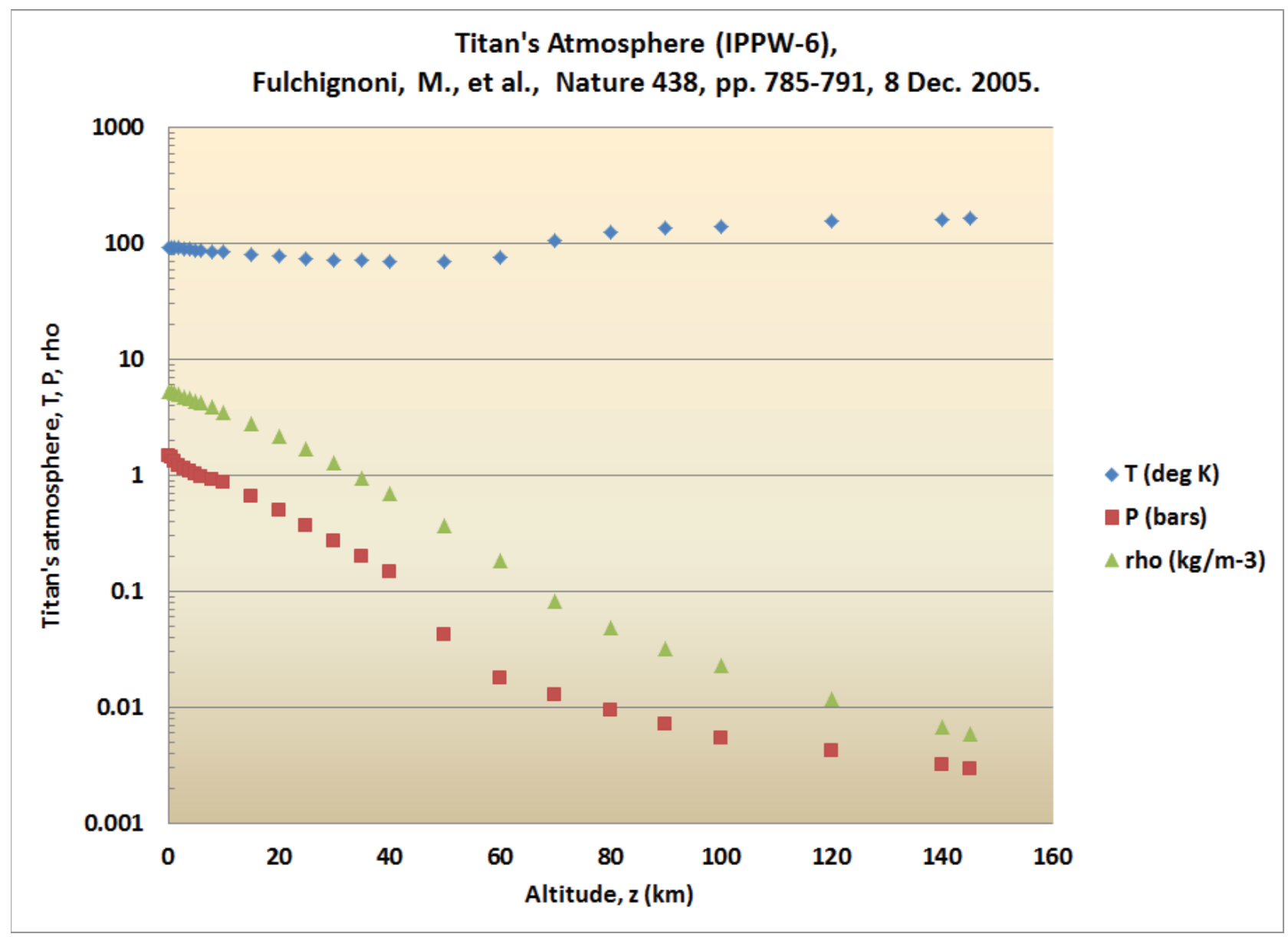


Appendix B: Jupiter mission analyses and data (Ref. 26)

Table 2. 10

\section{VELOCITY REQUIREMENTS FOR A SELEC IED JUPITER (CALLISTO OREIT) MISSION}

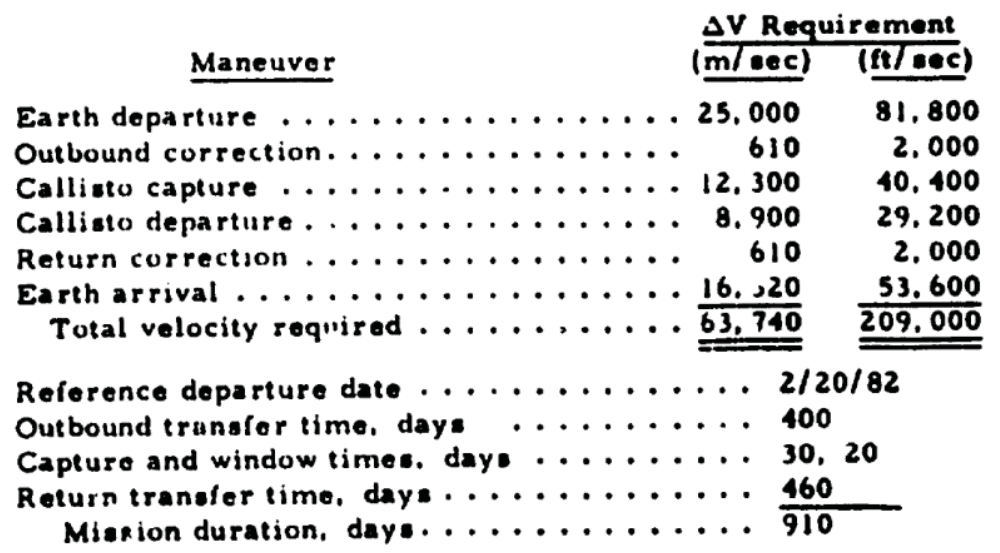

Table B1: Jupiter mission data (Ref. 26)

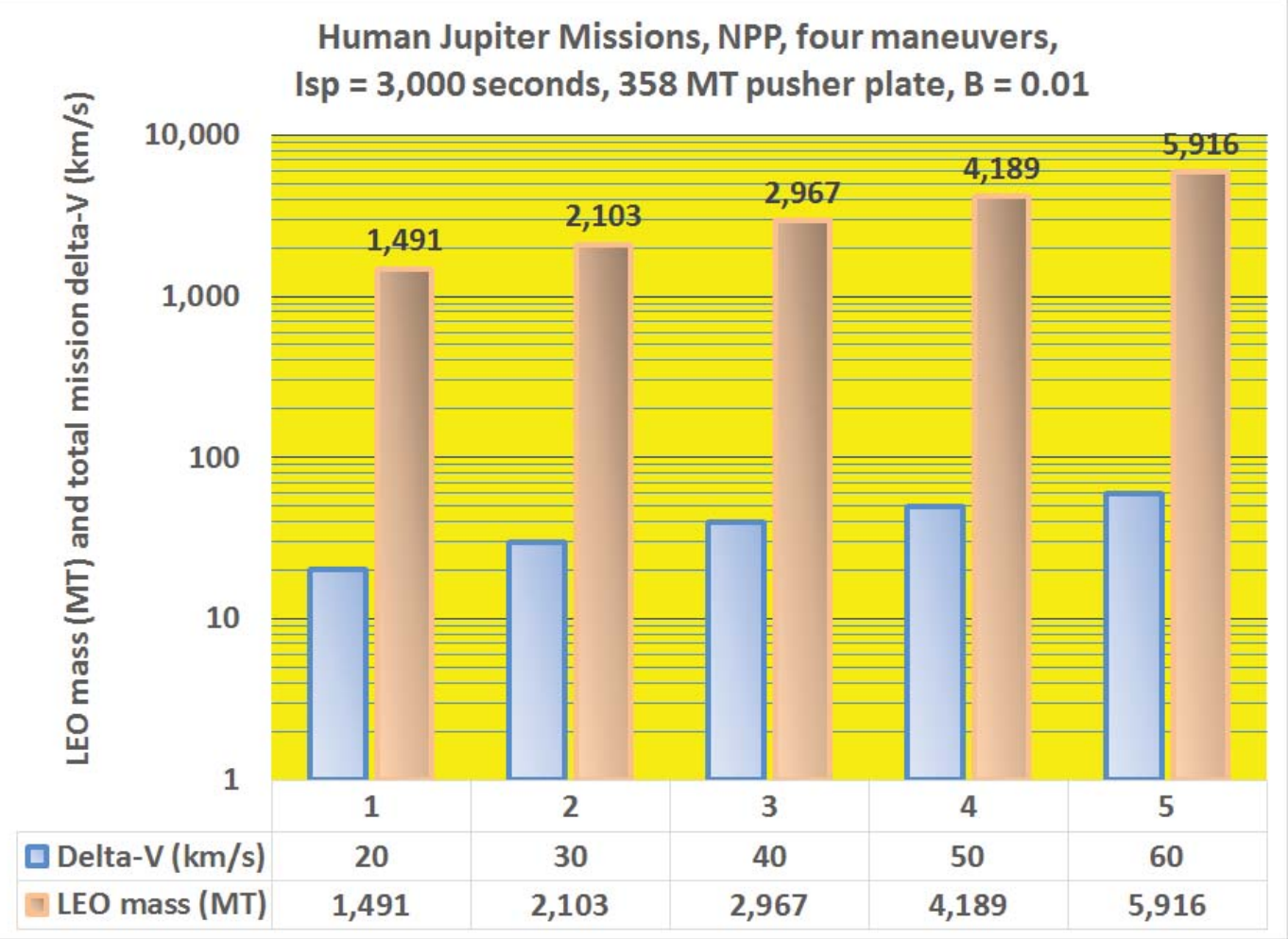

Figure B1: Jupiter mission data 
Appendix B: continued

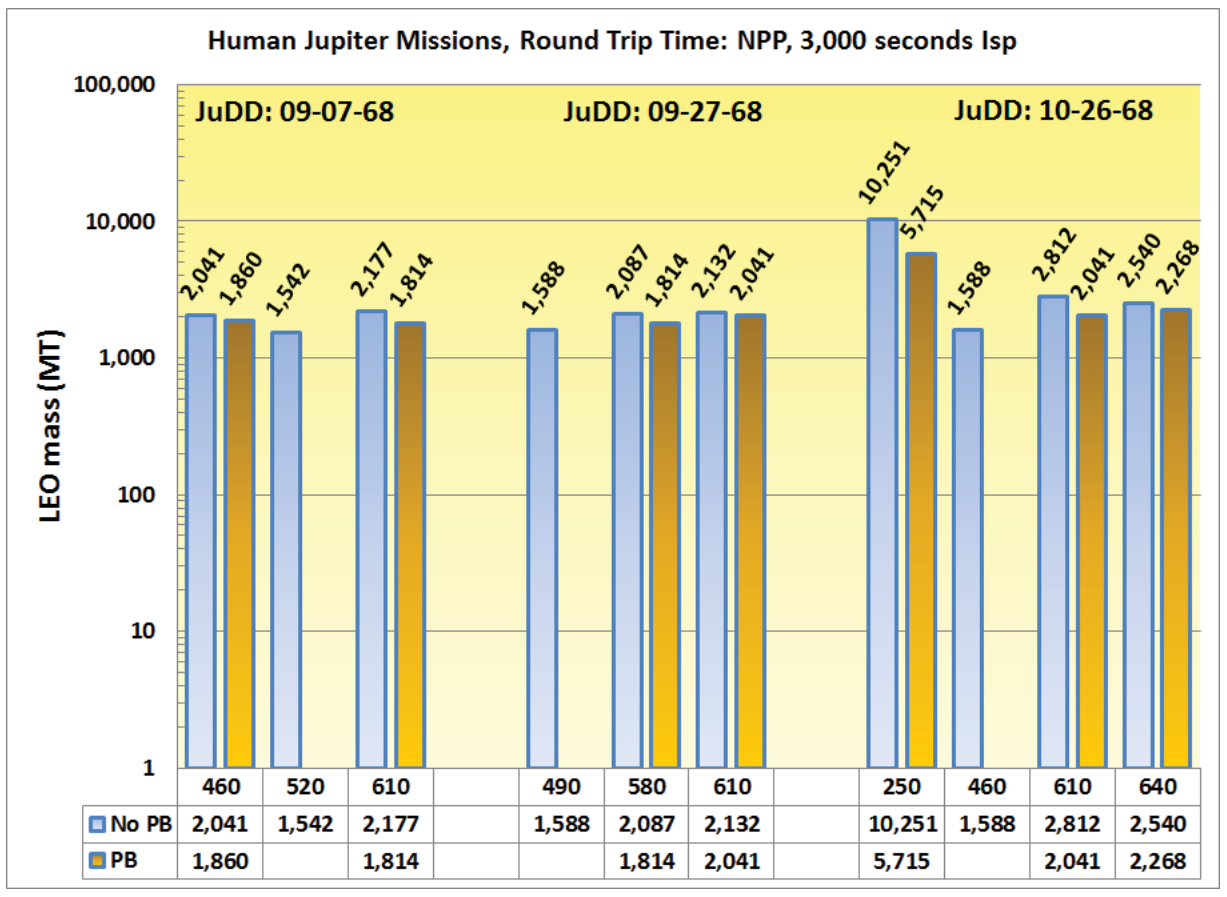

Figure B2. Human Jupiter missions using NPP (data from Ref. 26)

Tab. 3.4 JUPITER MISSION DATA

\begin{tabular}{|c|c|c|c|c|c|c|c|c|c|c|c|c|c|}
\hline Planet & EADD & $\begin{array}{c}T_{1} \\
\text { (dayo) }\end{array}$ & $\begin{array}{c}v_{\infty 1}^{*} \\
(\text { EMOS })\end{array}$ & $\begin{array}{c}\Delta v_{1} \\
(f t / s+c)\end{array}$ & $\left\{\begin{array}{c}v_{m 2}^{*} \\
\text { (EMOS) }\end{array}\right.$ & $\begin{array}{c}\Delta V_{2} \\
\left(n=3: r^{t}=1.3\right) \\
(t t / \text { sec })\end{array}$ & $\begin{array}{c}T_{\text {cpt }} \\
\text { (dayof }\end{array}$ & JuDD & $\begin{array}{c}T_{2} \\
(\text { deye) }\end{array}$ & $\begin{array}{c}v_{-3}^{*} \\
\text { (EMOS) }\end{array}$ & $\begin{array}{c}\Delta v_{3} \\
(f t / t e c)\end{array}$ & $\begin{array}{c}v_{\propto 4}^{*} \\
\text { (EMOS) }\end{array}$ & $\left(10^{3} \mathrm{St}_{\mathrm{s}}^{\mathrm{V} / \text { eec })}\right.$ \\
\hline Ju & $\begin{array}{c}12 / 3-12 / 21 \\
1980\end{array}$ & 460 & - & 28.000 & - & \begin{tabular}{l|}
33.000 \\
10.000 \\
$(n=30)$
\end{tabular} & - & - & - & - & - & - & - \\
\hline Ju & $\begin{array}{l}12 / 29.1981- \\
1 / 22.1982\end{array}$ & 460 & 0.4 & 27.300 & 0.53 & $\begin{array}{l}33,000 \\
10,000 \\
(n=30)\end{array}$ & - & - & - & - & - & - & - \\
\hline Ju & $\begin{array}{c}2 / 3-2 / 17 \\
1983\end{array}$ & 460 & 0.38 & 24,700 & 0.513 & $\begin{array}{c}32.000 \\
9.600 \\
(n=30)\end{array}$ & - & - & - & - & - & - & - \\
\hline Ju & $\begin{array}{c}3 / 8-3 / 21 \\
1984\end{array}$ & 460 & 0.37 & 24.400 & 0.492 & $\begin{array}{r}32,000 \\
9,600 \\
(n=30)\end{array}$ & - & - & - & - & - & - & - \\
\hline Ju & $\begin{array}{c}1 / 0-4 / 28 \\
1985\end{array}$ & 160 & 0.37 & 24.400 & 0.472 & $\begin{array}{c}31.500 \\
8.600 \\
\{n=30\}\end{array}$ & - & - & - & - & - & - & - \\
\hline Ju & $\begin{array}{c}5 / 18-6 / 6 \\
1986\end{array}$ & 460 & 0.37 & 24.100 & 0.456 & $\begin{array}{r}30,000 \\
8,200 \\
(n=30)\end{array}$ & 10 & $\begin{array}{l}10 / 15 \\
1987\end{array}$ & $\$ 20$ & 0.39 & $\begin{array}{c}29,500 \\
6,900 \\
\{n=30\}\end{array}$ & 0.10 & 54,000 \\
\hline Ju & $\begin{array}{c}6 / 247 / 9 \\
1987\end{array}$ & 460 & 0.36 & 24. 100 & 0.452 & $\begin{array}{r}31,000 \\
8,200 \\
(n=30)\end{array}$ & 72 & $\begin{array}{r}12 / 22 \\
1988\end{array}$ & 460 & 0.162 & $\begin{array}{r}31.200 \\
8,200 \\
(n=30)\end{array}$ & 0.40 & 54,000 \\
\hline Ju & $\begin{array}{c}8 / 2-8 / 17 \\
1988\end{array}$ & 460 & 0.38 & 24,700 & 0.46 & $\begin{array}{l}31,200 \\
8,300 \\
(n=30)\end{array}$ & 79 & $\begin{array}{l}1 / 28 \\
1990\end{array}$ & 460 & 0.478 & $\begin{array}{r}31.500 \\
8.700 \\
(n=30)\end{array}$ & 0.40 & 54,000 \\
\hline Ju & $\begin{array}{c}9 / 6-9 / 21 \\
1989\end{array}$ & 460 & $0: 39$ & 25,000 & 0.48 & $\begin{array}{r}33,000 \\
8,800 \\
(n=30)\end{array}$ & 79 & - & 160 & 0.498 & $\begin{array}{r}32,000 \\
9,200 \\
(n \times 30)\end{array}$ & 0.40 & 54,000 \\
\hline
\end{tabular}

Table B2. Human Jupiter missions using NPP (Ref. 26) 